\title{
OPTIMASI ALGHORITMA BREADTH FIRST SEARCH PADA GAME ENGINE 3D THIRD PERSON SHOOTER MAZE BERBASIS AGEN CERDAS ANDROID
}

\author{
(SEARCH THE BLIND BREADTH FIRST SEARCH ALGORITHM IN 3D GAME ENGINE MAZE \\ THIRD PERSON SHOOTER ANDROID BASED ON INTELLIGENT AGENT )
}

\author{
Astrid Novita Putri \\ Fakultas Teknologi Informasi dan Komunikasi Program Studi Teknik Informatika \\ Universitas Semarang \\ astrid@usm.ac.id
}

\begin{abstract}
Game is currently very popular in the community at large, one of which is the game third person shooter (TPS) which can be run through a mobile phone or computer, making it very easy and affordable, one thrid person shooter game $3 D$ maze.The labyrinth is a game to find the right path to achieve the objectives which the way players experience many obstacles to destination, so spend a lot of time,then in need of a settlement in order to facilitate the player in completing the levels on every obstacle, in need of a alghoritm Breadth First Search for ease in completing permainan.Cara employment levels every alghoritm Breadth First Search is a search method that starts with the roots off the road to the next.This search is done by looking at all the nodes or vertices have the same level to determine the final outcome at that level,if they do not find the will to move to the next level. so that the process backtrackto re-find the right path to achieve goals the appropriate time.
\end{abstract}

Keywords - Games, Third person, Shooter, Maze, Breadth First Search.

\section{PENDAHULUAN}

Game sangat terkenal di kalangan masyarakat, dari anak-anak sampai dewasa seperti suatu bentuk hiburan yang mendukung hubungan interaksi sosial. Dengan perkembangan teknologi informasi dan komunikasi serta komputer dan perangkat keras yang canggih, telah menunjukkan potensi untuk membuat game di dalam komputer sangat baik. Salah Satu jenis permainan yang sangat popular di semua kalangan masyarakat adalah Third Person Shooter labirin (disingkat TPS) pada Game 3D Unity ini berisi suatu permainan yang berpusat pada senjata dan proyek memerangi senjata melalui sudut pandang orang pertama. Dalam sebuah game, termasuk dalam Third Person Shotter labirin diperlukan suatu penyelesaian menyelesaikan masalah pada game Third Person Shotter melewati jalan labirin yang bertujuan untuk memotivasi pemain agar lebih terpacu untuk menyelesaikan permainan hingga selesai.

Pada Penelitian ini peneliti akan berfokus mengenai Game Engine pada Player dan belum adanya penelitian yang membahas tema ini, pada Game Engine Third Person Shooter labirin, Bagaimana cara untuk menyelesaikan game ini yang menggunakan pola labirin, maka di butuhkan suatu agen cerdas Alghoritma Artifical Intelligece pencarian melebar pertama (Breadth First Search), untuk mempermudah pemain menyelesaikan misi, sehingga menantang pemain untuk menyelesaikan misi.

\section{LANDASAN TEORI}

A. Game Engine

Game engine adalah sebuah sistem perangkat lunak (software) yang di rancang sebagai pembuatan atau pengembangan suatu video game. Game Engine yang memberikan suatu kemudahan dalam menciptakan konsep pada suatu game yang akan di buat. Mulai dari sistem rendering, physics, arsitektur, suara, scripting, A.I., dan bahkan dalam sistem networking.

Contoh game engine sebagai berikut :

1. Construct Classic adalah Construct merupakan software untuk membuat game berbasis pemrograman $\mathrm{C}++$ dengan menggunakan event base yang mempermudah gamer utuk membuat game

2. Game Maker merupakan suatu game berbasis pemrograman $\mathrm{C}++$ dengan menggunakan event block.

3. Unity Engine sebuah game engine unity yang memungkinkan developer untuk membuat game berbasis $2 \mathrm{~d}$ maupun $3 \mathrm{~d}$.

4. Unreal Engine adalah sebuah software untuk mendevelop game terbaru yang tergolong sangat powerfull untuk membuat suatu game. [1] 


\section{B. Game Labirin}

Permainan game labirin adalah suatu permainan yang terlihat sangat sederhana tetapi mampu untuk menyelesaikajn suatu teka-teki logika dimana menyelesaikannya dan tampilanya dari sudut pandang 3D, tingkatan game ini tergantung pada penyelesaian rute perjalanan yang harus di lalui dari jalur yang tepat. Dengan object dan keyboard menekan tombol panah atas dan bawah, ke depan dan belakang, ke kanan dan kiri.Hingga menemukan jalan keluar, batas waktu yang di berikan waktu adalah 5 menit untuk menyelesaikan, jika belum selesai maka timeout dan mengulang dari awal kembali.

Permainan labirin adalah permainan mencari jalan keluar, dari beberapa jalur pada suatu area permainan. Template permainan berbentuk persegi atau persegi panjang yang ukurannya dapat diatur sesuai dengan keinginan user. Di dalamnya terdapat serangkaian jalur berupa labirin yang bercabang, namun tidak setiap cabang labirin tersebut merupakan jalan keluar karena ada yang terhalang oleh temboktembok penghalang. [2]

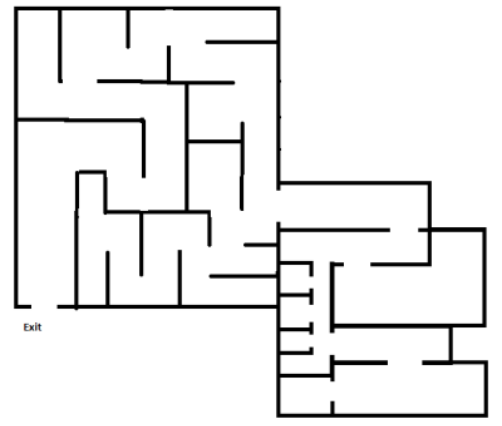

Gambar 1 Game 3D Labirin

\section{Agen Cerdas}

Permainan atau aplikasi yang dirancang menggunakan agen cerdas sebagi otak untuk melawan manusia. Agen adalah sesuatu yang dapat mengesan lingkungannya melalui sensors dan mengambil indakan terhadap lingkungannya melalui actuators.Agen yang berinteraksi dengan lingkungan melalui actuators.Agen yang berinteraksi dengan lingkungan melalui sensors dan actuators dapat dilihat pada gambar 1.

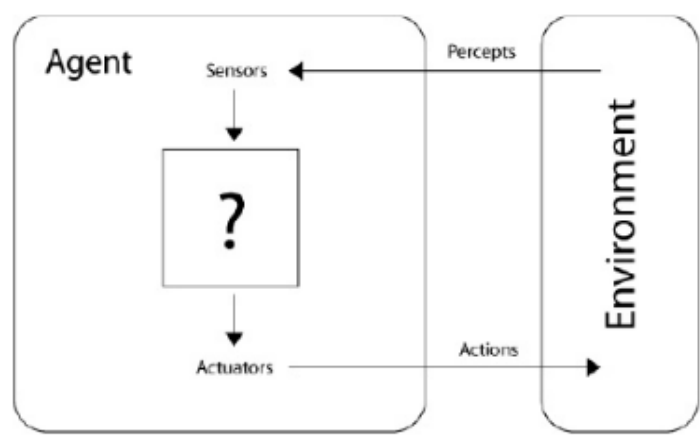

Gambar 2 Agen yang bernteraksi dengan lingkungan melalui sensors dan actuators
Definisi agen rasional adalah untuk setiap deretan persepsi yang mungkin,sebuah agen rasional hendaklah memilih satu tindakan yang diharapkan memaksimalkan ukuran perfomance-nya dengan adanya bukti yang di berikan oleh deretan presepso apapun pengetahuan terpasang yang dimiliki agen itu.Empat agen dasar yaitu simple reflex agents,model-based reflex agents, goal-based agents dan unity-based agents.[3]

\section{Alghoritma Breadth First Search (BFS)}

Metode pencarian yang di mulai dengan akar (Level 0) ke level selanjutnya.Pencarian ini di lakukan dengan mencari pada semua node atau simpul yang mempunyai level atau tingkatan sama sampai mennetukan hasil akhir (Goal) pada level tersebut, bila tidak aka akan pindah ke level selanjutnya. [4]

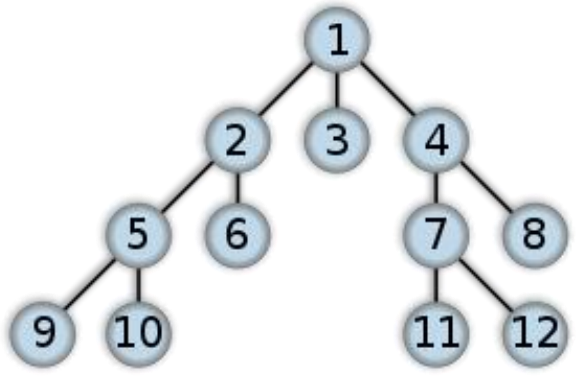

Gambar 3 Alghoritma Breadth First Search

Langkah-Langkah Alghoritma Breadth First Search

1. Masukkan node akar ke dalam Queue.

2. Ambil node awal Queue, lalu cek apakah node merupakan solusi.

3. Jika node merupakan solusi, pencarian selesai dan hasil di kembalikan.

4. Jika node untuk solusi, masukkan seluruh node anak ke dalam Queue.

5. Jika Queue kosong dan setiap node sudah di cek, pencarian selesai.

6. Jika Queue tidak kosong, ulangi pencarian mulai dari poin 2. [4]

E. Unity 3D

Unity 3D adalah sebuah software development yang terintegrasi untuk menciptakan video game atau konten lainnya seperti visualisasi arsitektur atau real-time animasi 3D. Unity 3D dapat digunakan pada microsoft Windows dan MAC OS X, dan permainan yang dihasilkan dapat dijalankan pada Windows, MAC, Xbox 360, OlayStation 3, Wii, iPad, iPhone, Android dan Linux. Unity 3D juga dapat menghasilkan permainan untuk browser dengan menggunakan plugin Unity Web Player. Unity 3D juga memiliki kemampuan untuk mengekspor permainan yang dibangun untuk fungsionalitas Adobe Flash 3D. [5] 


\section{F. Finite State Machine}

Finite State Machine (FSM) merupakan pemodelan dari perilaku (behavior) sebuah sistem atau obyek yang kompleks dengan beberapa kondisi atau mode yang terdefinisikan dimana mode transisi berubah sesuai dengan keadaan. Finite State Machine terdiri dari empat elemen utama :

a. State yang mendefinisikan kelakuan dan mungkin menghasilkan aksi.

b. Transisi state dimana merupakan perpindahan dari satu state ke state lain.

c. Aturan atau kondisi yang harus dipenuhi supaya ada transisi state kejadian (events).

d. Input yang terjadi baik internal maupun external, yang memungkinkan trigger aturan dan mengacu ke transisi state. [6] [7].

Alur pada diagram state dapat dilihat pada gambar dibawah ini pada gambar 4 terdapat contoh alur state Finite State Machine.

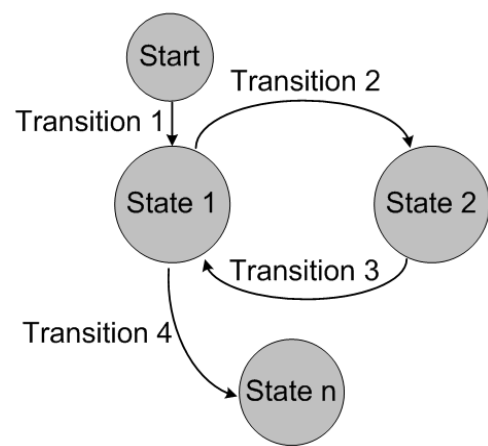

Gambar 4 Contoh Diagram State Sederhana

\begin{tabular}{|c|}
\hline MASALAH \\
\hline $\begin{array}{c}\text { Sulitnya pemain menyelesaikan misi game hingga selesai, } \\
\text { karena harus melewati beberapa halangan dan jalan melalui } \\
\text { labirin. }\end{array}$
\end{tabular}

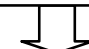

\begin{tabular}{|c|c|c|}
\hline \multicolumn{3}{|c|}{ PENDEKATAN METODE } \\
\hline \multicolumn{3}{|c|}{ Alghoritma Breadth First Search (BFS) } \\
\hline & $\zeta$ & \\
\hline \multicolumn{3}{|c|}{ PENGGEMBANGAN GAME } \\
\hline $\begin{array}{l}\text { Spesifikasi } \\
\text { Desain : } \\
\text { Storyboards, } \\
\text { FSM }\end{array}$ & $\begin{array}{c}\text { Coding : Unity } \\
\text { C\# }\end{array}$ & $\begin{array}{l}\text { Pengujian Sistem } \\
\text { : Finish Time, dan } \\
\text { Black Box }\end{array}$ \\
\hline \multicolumn{3}{|c|}{\llcorner} \\
\hline \multicolumn{3}{|c|}{ HASIL PENELITIAN } \\
\hline \multicolumn{3}{|c|}{$\begin{array}{l}\text { Menyelesaikan jalan keluar secara optimalisasi melalui } \\
\text { permainan labirin dengan mudah karena menggunakan } \\
\text { alghoritma pencarian di bantu menggunakan metode } \\
\text { Alghoritma Breadth First Search (BFS) dari player tersebut }\end{array}$} \\
\hline
\end{tabular}

Gambar 5 Kerangka Pikir Penelitian
Penelitian yang akan dilakukan peneliti adalah penggunaan arificial intelligent dengan Alghoritma Breadth First Search (BFS) untuk membantu Player dalam menemukan jalan keluar labirin sehingga mempermudah player untuk menyelesaikan misi.

\section{PENELITIAN TERKAIT}

\begin{tabular}{|c|c|c|c|c|}
\hline No & $\begin{array}{c}\text { Nama } \\
\text { Penelitian }\end{array}$ & Jurnal & Hasil & Kekurangan \\
\hline 1. & $\begin{array}{c}\text { Penerapan } \\
\text { Algoritma } \\
\text { Backtracki } \\
\text { ng Pada } \\
\text { Permainan } \\
\text { Math Maze } \\
\text { [10] }\end{array}$ & $\begin{array}{c}\text { Pelita } \\
\text { Informatika } \\
\text { Budi } \\
\text { Darma, } \\
\text { Volume } \\
\text { VII, Nomor } \\
: \text { 3, Agustus } \\
2014 .\end{array}$ & $\begin{array}{c}\text { Penerapan } \\
\text { algoritma } \\
\text { ditetapkan } \\
\text { dengan angka } \\
\text { angka sisi kiri } \\
\text { dan sisi atas } \\
\text { didalam } \\
\text { permainan } \\
\text { math maze. }\end{array}$ & $\begin{array}{c}\text { Penerapan } \\
\text { alghoritma } \\
\text { di tentukan } \\
\text { harus } \\
\text { melewati } \\
\text { jalur yang di } \\
\text { tetapkan, } \\
\text { hanya } \\
\text { menggunaka } \\
\text { n visual } \\
\text { basic, belum } \\
\text { berbentuk } \\
\text { 3D }\end{array}$ \\
\hline 2 & $\begin{array}{c}\text { Penggunaa } \\
\text { n Metode } \\
\text { Kecerdasan } \\
\text { Buatan } \\
\text { Runut } \\
\text { Maju Dala } \\
\text { Memecahk } \\
\text { an } \\
\text { Permasalah } \\
\text { an Game } \\
\text { Labirin } \\
\text { [11] }\end{array}$ & $\begin{array}{c}\text { Jurnal Ilmu } \\
\text { Komputer- } \\
\text { Volume 5- } \\
\text { No.1-April } \\
2012 \\
\text { Universitas } \\
\text { Udaya }\end{array}$ & $\begin{array}{c}\text { Hasil eksekusi } \\
\text { program yang } \\
\text { dibuat } \\
\text { berdasarkan } \\
\text { konsep } \\
\text { kecerdasan \& } \\
\text { model } \\
\text { pemikiran } \\
\text { memiliki } \\
\text { urutan jalan } \\
\text { yang sama } \\
\text { dengan hasil } \\
\text { penyelesaian } \\
\text { apabila } \\
\text { masalah } \\
\text { tersebut dicari } \\
\text { secara manual }\end{array}$ & $\begin{array}{c}\text { Belum di } \\
\text { implemetasi } \\
\text { kan ke } \\
\text { bahasa } \\
\text { pemrograma } \\
\text { n. }\end{array}$ \\
\hline
\end{tabular}

Tabel 1 Penelitian Terkait

Berdasarkan Beberapa Penelitian di atas dapat di simpulkan bahwa [10] [11] belum jelasnya penelitian mengenai game labirin, dan belum terselesaikannya masalah menyelesaikan game labirin dari titik awal hingga akhir dari titik akhir menggunakan alghoritma dalam bahasa pemrograman dan game nyata 3D sehingga mempermudah pemain dalam menyelesaikan misinya. 


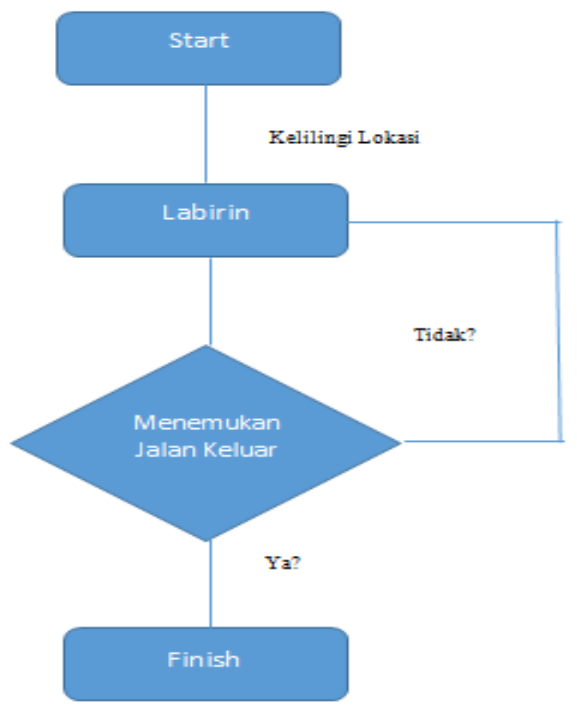

Gambar 6 Flowchart Game Labirin Third Person Shotter

\section{a. Tampilan Game Labirin Third Person Shotter}

Perkembangan industry game sekarang ini sangat pesat dari segi grafis dan Artifical Intelligent-nya. Penelitian ini akan meneliti mengedepankan pada menyelesaikan game labirin

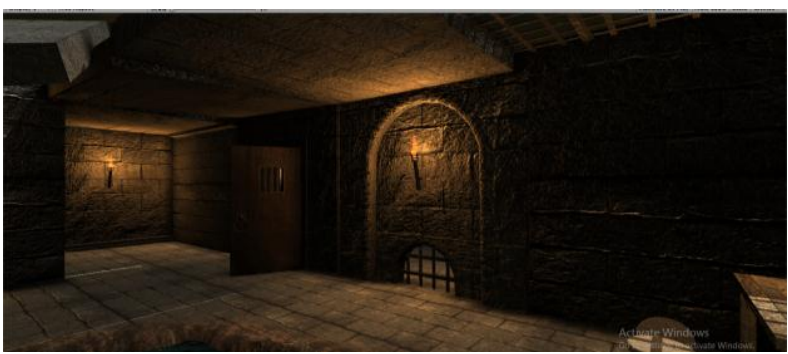

Gambar 7 Tampilan Game Ketika Player Menghampiri Setelah Memburu Jalan Keluar

Pada gambar di bawah ini adalah jalan labirin pada game labirin Third Person Shooter di lihat dari sudut y .

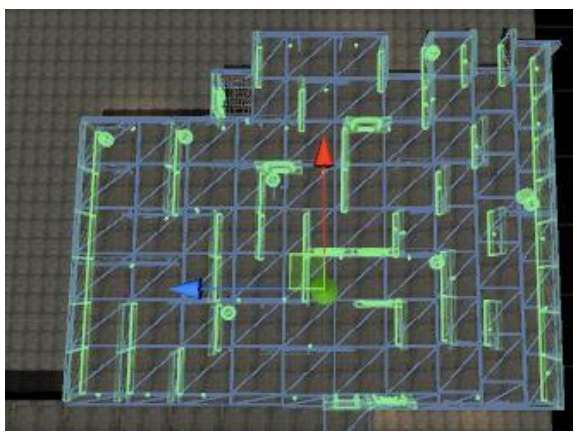

Gambar 8 Tampilan Game Labirin Third Person Shooter
Pada gambar selanjutnya adalah gambar tampilan design game Labirin Third Person Shooter di desain di tampilkan di dalam ruangan dalam posisi kurang cahaya sehingga memberikan kesan horor dan di lengkapi dengan efek api cahaya pada penerangan setiap jalan dalam sudut labirin.

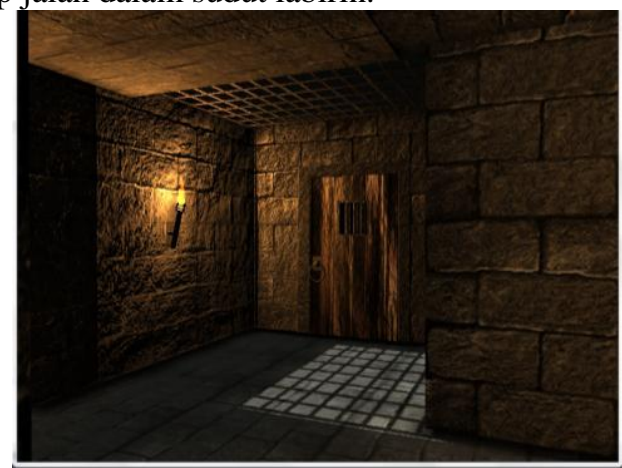

Gambar 9 Tampilan Pintu Keluar Game Third Person Shooter

\section{HASIL PENELITAN DAN PEMBAHASAN}

a. Analisa Alghoritma Breadth First Search pada Game Third Person Shotter (BFS)

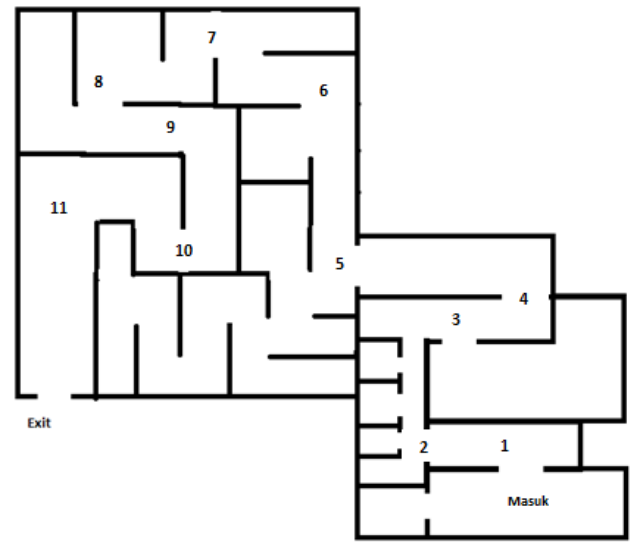

Gambar 10 Analisa Penyelesaian pada game menggunakan metode Alghoritma Breadth First Search.

Pada penjelasan di atas di atas dapat di simpulkan bahwa Alghoritma Breadth First Search, pencarian buta pada semua node pada level $\mathrm{n}$ dan di kunjungi terlebih dahulu sebelum mengunjungi node node pada level $n+1$. Pencarian di mulai dari node masuk ke node exit, kemudian berpindah ke level berikutnya, demikian pula dari kanan ke kiri hingga menemukan goal.

\section{b. Finite State Machine}

Kriteria yang ada di dalam Game Labirin Third Person Shooter Dengan Alghoritma Breadth First Search dapat dijelaskan pada Finite State Machine sebagai berikut : 


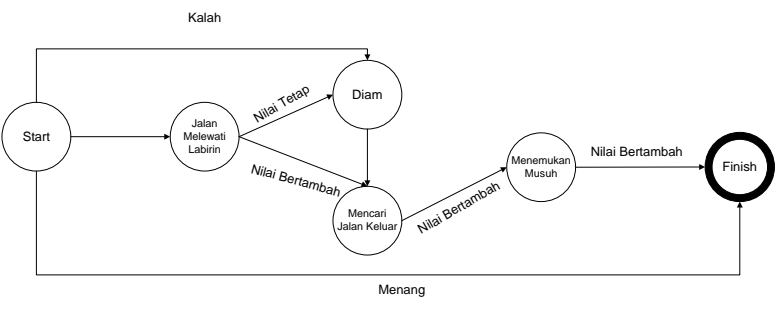

Gambar 11 FSM Game Labirin Third Person Shooter Dengan Alghoritma Breadth First Search.

c. Implementasi Pada Game Labirin Third Person Shooter dengan menggunakan Unity 3D

Listing Coding Alghoritma Breadth First Search pada Game Third Person Shotter

1. private void ProgressStepCycle(float speed)\{

2. if (m_CharacterController.velocity.sqrMagnit ude > $0 \& \&$ (m_Input.x != $0 \|$ m_Input.y !=0) )

$\{$ m_StepCycle $+=($ m_CharacterController.vel ocity.magnitude $+(\operatorname{speed} *($ m_IsWalking ? 1f : m_RunstepLenghten)))*Time.fixedDeltaTim $\mathrm{e} ;\}$

3. if $\left(!\left(m \_S t e p C y c l e>m \_N e x t S t e p\right)\right)\{$ return; $\}$ $\mathrm{m} \_$NextStep $=\mathrm{m} \_$StepCycle $+\mathrm{m} \_$StepInterval \};

4. Private void bfs(int $\mathrm{x}$, int $\mathrm{z}$, int depth, float jump, float previousHeight)

5. $\quad$ int resistance $=1$;

6. if (depth $>=0$ ) $\quad$ CheckTile $(\mathrm{x}, \mathrm{z})$.GetComponentInChildren(CheckIfClicke d)().Selected();

7. if $(x+1<25)\{$ CheckTile $(x+1, z$, depth, jump, previous Height);

8. if $(x-1>=0)\{$

CheckTile(x-1, z, depth, jump, previousHeight $) ;\}$

9. if $(\mathrm{z}+1<25)\{$ CheckTile(x, z+1, depth, jump, previousHeight);

10. if $(\mathrm{z}-1>=0)\{$

11. CheckTile(x, z-1, depth, jump,previousHeight); \}\} \}

12. private void CheckTile(int $\mathrm{x}$, int $\mathrm{z}$, int depth, float jump, float previousHeight $)\{$

13. float tileHeight $=$ tiles $(\mathrm{x}$, z).GetComponent(TileDimensions)().height; float difference $=$ tileHeight - previousHeight;

14. if (difference $<0)$ difference $*=-1$;

15. if $\operatorname{CheckTile}(\mathrm{x}, \mathrm{z})$. GetComponentInChildren.CheckIfClicked().o ccupied \&\& difference(jump); \{

16. int resistance $=$ tiles $(\mathrm{x}$, z).GetComponent(TileDimensions)().getResis tance();

17. if $($ resistance $<0)$ resistance $=1 ; \operatorname{BFS}(x, \quad z$, depth-resistance, jump, tileHeight); \} \}

\section{KESIMPULAN}

Hasil dari eksperimen penelitian mengenai Game Third Person Shooter labirin maka dapat di simpulkan sebagai berikut : implementasi game Third Person Shooter labirin menggunakan Alghoritma Breadth First Search dapat menyelesaikan hasil dengan titik yang di gunakan untuk mempermudah jalannya player untuk menyelesaikan game tersebut. Berdasarkan hasil testing, ada beberapa pengujian yang digunakan dalam game ini yaitu Pengujian interface yang menguji fungsi - fungsi game secara interface ke pemain berhasil diterima dengan baik. Kemudian ada pengujian skenario dari 50 kali percobaan game dapat melakukan skenario yang diujikan menggunakan metode Alghoritma Breadth First Search, sedangkan dengan metode lain atau tanpa metode ada beberapa yang tidak bisa dilakukan sesuai dengan harapan. Dan akurasi yang di dapat adalah $85 \%$ pada pengujian testing dan pada akhirnya dapat disimpulkan bahwa metode Alghoritma Breadth First Search dalam masalah finish time lebih lama tetapi akan memudahkan pemain untuk menyelesaikan dengan cepat.

Saran :

a. Pada penelitian ini di fokuskan pada Game Third Person Shooter labirin, sedangkan jika tema labirin sangat luas yaitu Penerapan Alghoritma Backtracking Pada Permainan Maze, Penggunaan Metode Kecerdasan Buatan Runut Maju Dalam Memecahkan Permasalahan Game Labirin,dan sebagainya menggunakan Mungkin untuk penelitian selanjutnya dapat menambahkan kekurangan pada peneliti sekarang.

b. Environment game dapat dikembangkan lagi dengan menambahkan berapa effect sehingga game lebih menarik para pemain, sehingga game yang dimainkan lebih realistis.

1. Alur cerita game dapat dikembangkan sehingga dapat memperbanyak level game yang semakin menantang.

2. Untuk labiirin game dapat di tambahkan parameter dengan metode lain sehingga ada perbandingan banyak metode.

Untuk keterangan gambar di bawah ini yang pada bagian kiri adalah tanpa menggunakan alghoritma, sehingga dalam menyelesaikan permainan lebih lama, sedangkan dibandingkan dengan menggunakan Alghoritma Breadth First Search pada bagian kanan menunjukan bahwa Alghoritma Breadth First Search lebih cepat menyelesaikan permainan dibandingkan dengan tanpa menggunakan alghoritma, sehingga mempermudah pemain dalam menyelesaikan permainan game labirin thrid person shooter. 


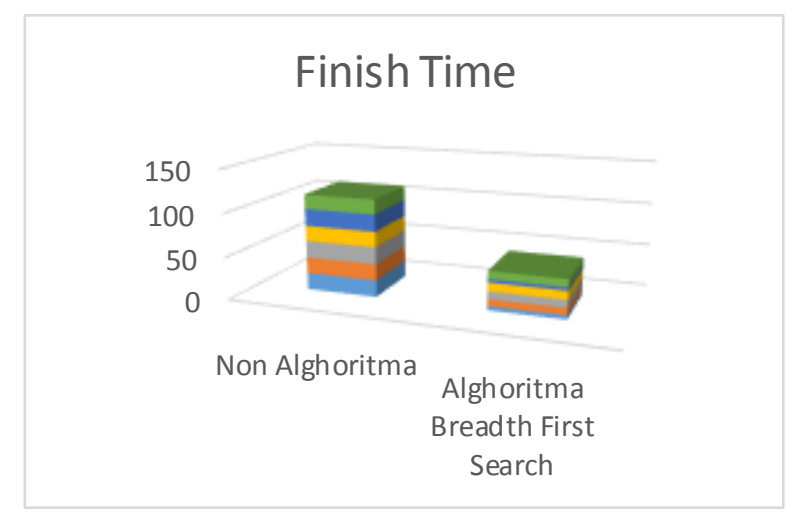

Gambar 11 Hasil Pengujian antara Metode Alghoritma Breadth First Search dan tanpa metode dengan Waktu Penyelesaian Permainan.

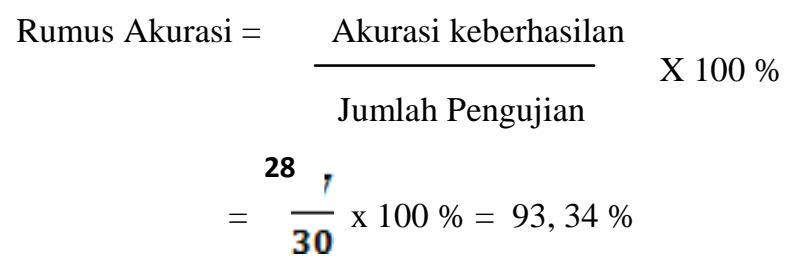

\section{DAFTAR PUSTAKA}

1. Fairuz Moch. Shiratudin Walid Thabet, "Utilizing a 3D Game Engine to Develop a Virtual Review System”, Jurnal of information Technology in Construction, January 2011, ISSN : 1874-4752.

2. Santi I Gede, "Penggunaan Metode Kecerdasan Runut Maju Dalam Memecahkan Permasalahan Game Labirin," Jurnal Ilmu Komputer Volume 5 No 1-April 2012.

3. Stuart, Russel and Peter Norvig., " Artifical Inteligence A Modern Approach.", 2 Edition.United States Of America Prentice Hall, 2005

4. Sutojo,dkk, "Kecerdasan Buatan".Penerbit Andi, 2011.

5. Novita Astrid ,dkk, "Game Scoring Supporting objects Menggunakan Agen Cerdas Berbasis Fuzzy Mamdani”. Jurnal Transformatika. 2016

6. Nendya Bhakti Matahari,"Pemetaan perilaku non-playable character pada permainan berbasis role playing game menggunakan metode finite state machine", Teknik Informatika, Fakultas Teknologi Informasi, Universitas Kristen Duta Wacana Yogyakarta, 2011.

7. Kim, C.H., Jeong, S.M,. Hur, G.T., dan Kim, B.G. (2006), "Verification of FSM using Attributes Definition of NPCs Models", IJCSNS International Journal of Computer Science and Network Security, VOL.6 No.7A, July 2006.168-174.
8. Nasution Rahmad, "Penerapan Alghoritma Backtracking Pada Permainan Math Maze”, Jurnal Pelita Informatika Budi Darma, Volume VII, Nomor : 3, Agustus 2014.

9. Santi I Gede Astawa," Penggunaan Metode Kecerdasan Buatan Runut Maju Dalam Memecahkan Permasalahan Game Labirin”, Jurnal Ilmu Komputer-Volume 5- No.1-April 2012 Universitas Udaya 